\title{
AiMT
}

Advances in Military Technology

Vol. 12, No. 2 (2017), pp. 217-228

ISSN 1802-2308, eISSN 2533-4123

DOI 10.3849/aimt.01185

\section{A Quantitative Method of Comparative Assessment of Primers Ignition Performances}

\author{
D.A. Goga ${ }^{1}$, T.V. Țigănescu ${ }^{1}$, B. Pulpea ${ }^{1}$, C. Moldoveanu ${ }^{1}$ and C. Rotaru ${ }^{2 *}$ \\ ${ }^{1}$ Military Technical Academy, Bucharest, Romania \\ ${ }^{2}$ Henri Coanda - Air Force Academy, Brasov, Romania
}

\begin{abstract}
The manuscript was received on 14 March 2017 and was accepted after revision for publication on 27 October 2017.
\end{abstract}

\begin{abstract}
:
The ignition performances of percussion primers for small calibre ammunition are determined using a new experimental setup, with pressure transducers and special designed combustion chambers. The method enables a comparison of new designed primers with consecrated models by relative ignition capacity. Results show that ballistic performances of primers are in direct relationship with the gradient pressure vs. rise time and also with the maximum pressure developed inside the cartridge chamber.
\end{abstract}

\section{Keywords:}

ammunition, percussion primers, ignition, ballistic

\section{Introduction}

The safety and the reproducibility of the interior ballistic cycle for both large and small calibre gun systems are directly correlated with the propellant and primer energetic and mechanical properties [1-3]. In fact, an important safety characteristic of any ammunition used in weapon systems is the maximum pressure in the cartridge chamber, whose value helps to avoid malfunctions, accidents or damages. The role of the ammunition developer is to choose suitable propellants and primers (percussion caps) in order to obtain the desired muzzle velocity (energy) without surpassing pressure limitations.

The choice of the perfect gun propellant for small calibre ammunition has not always been an easy task, but nowadays the energetic materials industry is able to provide formulations with various compositions and geometries, thus adjusting the combustion velocities and the combustion thickness for any ammunition-weapon

\footnotetext{
* Corresponding author: Aviation Department, Henri Coanda Air Force Academy, Mihai Viteazul 160, Brasov, Romania. Phone: +40 2684234 21, fax: +40 2684220 04, E-mail: rotaruconstantin@yahoo.com
} 
system. On the other hand, the choice for the primers, which are usually produced on-site in the ammunition factory, is quite limited to one or two sorts.

Meanwhile, standard procedures for new ammunition batches testing include for the primers only some chemical analyses on the primer mixtures and some percussion tests for the primers sensitivity determination (the minimum energy of percussion). The ignition capacity of the primer is basically tested in a system context during real firing tests. From experience, after testing an important number of ammunition batches, it has been observed that ballistic performances of ammunition often vary / fall even when using exactly the same quantity and sort of propellant for the propelling charge. While trying to develop new types of primers, Ritter [4] also concluded that primer's performance subsequently resulted in rather different cartridge performances. These observations immediately raised two questions: How the primer's ignition performances influence the ballistic performances of the ammunition? Which of the primer characteristics should be improved in order to obtain a perfect ignition of the gun propellant?

Analysing the state of the art, it has been found that very few references are encountered on this topic. In this sense, efforts were done for the characterization of propellant ignition process and primers properties, but most of them consisted in real firing of the fully equipped ammunition using laboratory weapons and analysing the ballistic parameters. These tests do not allow emphasizing primers role and only give a global estimation over the ammunition system performance. On the other hand, the method is very laborious and expensive and must be performed inside a firing range. Some methods presented in the literature [4-7] indicate the power or brisance of the primer as key factor in estimating the ignition capacity. Ritter [4] fired fully charged ammunition using a laboratory weapon equipped with a pressure transducer mounted at the side of the cartridge case. In another work [6], the primer was fixed in a cartridge shell, which was mounted on a ballistic pendulum. The maximum height was recorded and used to estimate the primer power. The length of the primer flame is another parameter mentioned by other authors [7]. But neither of these methods allows a detailed evaluation of the ignition process on a time scale.

The importance of finding quantitative, reliable and inexpensive methods to comparatively asses the ignition capacity of primers is more important nowadays, in the context of greener munitions development [8-10]. New designed green primers, such as lead-free primers with emerging greener explosives [11, 12], are supposed to replace consecrated toxic primers based on lead styphnate, barium nitrate and antimony sulphide. The rapid development of nano-scale thermite materials and newly born laser ignition systems require precise methods for qualitative assessment of the ignition capacity.

In this context, the aim of the study has been to present a quantitative experimental method for the determination of the functional characteristics and relative ignition capacity of percussion primers small calibre ammunitions.

\section{Theoretical Approach}

Percussion primers are mechanic-pyrotechnic devices used to initiate propellants deflagration in small calibre ammunition. Under the action of exterior stimuli (in this case, firing pin percussion) the priming mixture is submitted to deflagration or detonation. The hot reaction products expand in the cartridge case between propellants granules, producing further deflagration. 
In order to determine the relative ignition capacity of the primers, functional and ballistic characteristics, the following parameters were defined and proposed for measurement:

- Delay time $\left(t_{\mathrm{d}}\right)$ - the time elapsed between the moment when the firing pin touches the cap and the moment when reaction products flow out in the cartridge case;

- Functioning time $\left(t_{\mathrm{f}}\right)$ - the time necessary for all the reaction products to extend until maximum pressure is reached, where the time is taken from pressure vs. time diagrams;

- Maximum pressure $\left(p_{\max }\right)$ - the maximum value of pressure, measured inside the cartridge case (depending also on the free volume, which is the volume not occupied by the propellant);

- Pressure rising rate $(\mathrm{d} p / \mathrm{d} t)$ - the slope of the pressure versus time curve (measured in time sections where constant);

- Maximum impulse $\left(I_{\max }\right)$ - the area under $\mathrm{p}(t)$ curve, calculated as:

$$
I_{\max }=\frac{p_{\max } t_{\mathrm{f}}}{2} .
$$

- Relative force $\left(f_{\mathrm{r}}\right)$ - the ratio between tested primer force and a reference primer force (the reference primer being the primer that equips a similar ammunition that proved its ballistic characteristics and ignition capacity in service) calculated as:

$$
f_{\mathrm{r}}=\frac{p_{\max }}{p_{\max \text { ref }}} .
$$

- Relative vivacity $\left(V_{\mathrm{r}}\right)$ - the ratio between tested primer vivacity and reference primer vivacity, calculated as:

$$
V_{r}=\frac{\frac{\mathrm{d} p}{\mathrm{~d} t}}{\left(\frac{\mathrm{d} p}{\mathrm{~d} t}\right)_{\mathrm{ref}}} .
$$

- Average pressurizing velocity $(V)$ - the pressure wave velocity inside the cartridge case determined with two pressure transducers mounted along the case at known distance.

\section{Experimental Settings}

The method proposed consists in the pressure vs. time variation measurement developed by the reaction products of a percussion primer, in an empty volume, similar with that of the fully equipped cartridge. The functional characteristics are determined and, further, the relative initiation capacity can be calculated and compared with a reference primer.

The tested primers percussion was performed using standard devices, with falling steel balls, similar to those consecrated in primers sensitivity tests for $5.56 \times 45 \mathrm{~mm}$ and $9 \times 19 \mathrm{~mm}$ calibre ammunition [13-14].

Multiple pressure piezoelectric transducers mounted along the pressure chamber can be used in order to determine the flowing reaction products gas-dynamics and, 
further, to calculate the pressurizing velocity of the cartridge case when empty or occupied with granules. In order to simulate the volume occupied by the propellant, small steel balls were introduced inside the cartridge case. The number of steel balls necessary to simulate the propellant was determined using equation (4),

$$
N_{\mathrm{b}}=\frac{V_{\mathrm{p}}}{V_{\mathrm{b}}}=\frac{6}{\pi} \frac{\omega_{\mathrm{p}}}{\phi_{\mathrm{b}}^{3} \rho_{\mathrm{p}}},
$$

where: $N_{\mathrm{b}}$ - the number of balls; $V_{\mathrm{b}}-$ the single ball volume $\left[\mathrm{mm}^{3}\right] ; V_{\mathrm{p}}-$ the volume occupied by propellant $\left[\mathrm{mm}^{3}\right] ; \phi_{\mathrm{b}}-$ the ball diameter $[\mathrm{mm}] ; \omega_{\mathrm{p}}-$ the propellant quantity $[\mathrm{g}] ; \rho_{\mathrm{p}}-$ propellant real density $\left[\mathrm{g} / \mathrm{mm}^{3}\right]$.

\subsection{Apparatus}

Details regarding the combustion chamber (closed pressure vessel) are described in Fig. 1 and Fig. 2.

The measuring system consisted in:

- piezoelectric pressure transducers 4QP2000 with an average sensitivity of $8.42 \mathrm{pC} / \mathrm{bar}$;

- charge amplifier KISTLER 5023 with 1000 pC/V amplification element;

- peak reading system (oscilloscope or any other DAQ device, computer, printer);

- pressure measuring device (Fig. 2, Fig. 3 and Tab. 1);

- percussion system (firing pin, steel ball and energized electromagnet);

- $5.56 \times 45 \mathrm{~mm}$ cartridge cases equipped with primers (tested primers and reference primers).
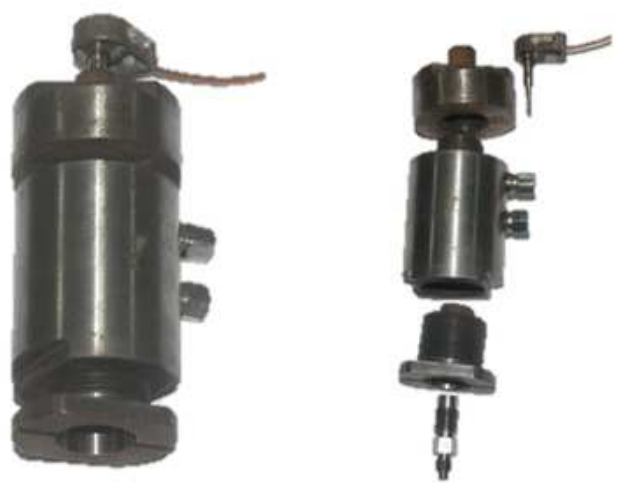

Fig. 1 Pressure measuring device: assembled and unassembled

Tab. 1 Pressure measuring device characteristics

\begin{tabular}{|c|c|c|c|c|c|c|}
\hline Type & $\begin{array}{c}\text { Volume of } \\
\text { cartridge } \\
\text { case } \\
W o\left[\mathbf{c m}^{3}\right]\end{array}$ & $\begin{array}{c}\text { Empty } \\
\text { volume with } \\
\text { propellant } \\
\text { charge } \\
V_{\text {real }}\left[\mathbf{c m}^{3}\right]\end{array}$ & $\begin{array}{c}\text { Number } \\
\text { of steel } \\
\text { balls } \\
\boldsymbol{\phi = 2 . 5}\end{array}$ & $\begin{array}{c}\text { Empty } \\
\text { volume } \\
\text { with steel } \\
\text { balls } \\
V_{\text {exp }}\left[\mathbf{c m}^{3}\right]\end{array}$ & $\begin{array}{c}\text { Transducers } \\
\text { position }\end{array}$ & $\begin{array}{c}\text { Distance } \\
\text { between } \\
\text { transducers }\end{array}$ \\
\hline \hline $5.56 \times 45$ & 1.90 & 0.980 & 112 & 0.984 & Perpendicular & $18 \mathrm{~mm}$ \\
\hline
\end{tabular}


During the experiments, Boxer type primers were used, kindly provided by U.M. SADU-Gorj S.A. There were employed four sorts of primers, their chemical composition submitted by the manufacturer being presented in Tab. 2 .

Tab. 2 Primer mixtures of Romanian primers

\begin{tabular}{|c|c|c|c|c|}
\hline \multirow{2}{*}{ Component } & \multicolumn{4}{|c|}{ Mass ratio [\%] } \\
\cline { 2 - 5 } & Batch "P” & Batch "1" & Batch “2” & Batch "3"' \\
\hline \hline Lead styphnate & 41 & 41 & 41 & 40 \\
\hline Tetracene & 3 & 3 & 3 & 3 \\
\hline Barium nitrate & 36 & 41 & 46 & 44 \\
\hline Antimony sulphide & 15 & 10 & 10 & 13 \\
\hline Al-Mg & 5 & - & - & - \\
\hline Mg & - & 5 & - & - \\
\hline Mixture charge [mg] & 20.0 & 20.2 & 21.8 & 22.2 \\
\hline
\end{tabular}

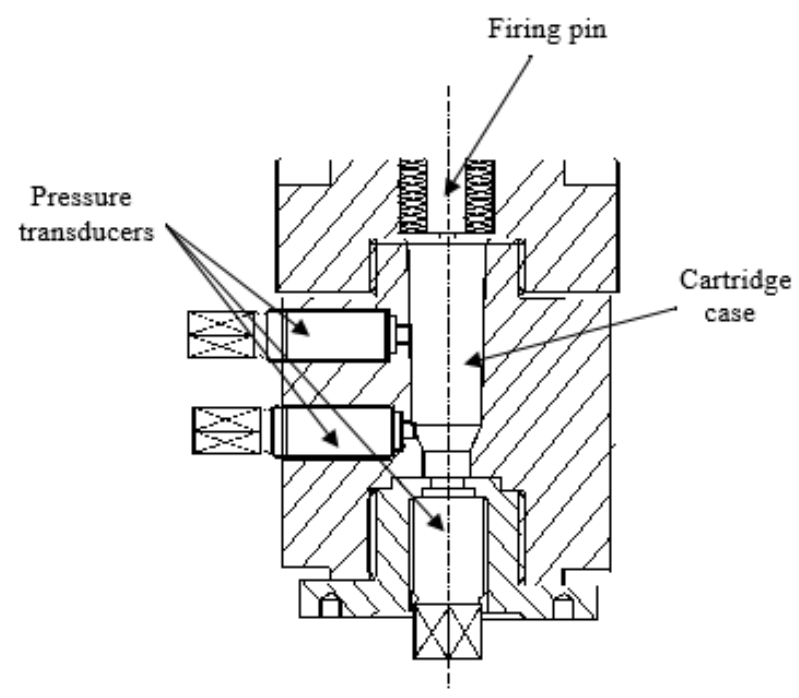

Fig. 2 Testing pressure chamber (section)

Additional tests were performed using consecrated ammunitions, respectively $5.56 \times 45 \mathrm{~mm}$ cartridge cases from Giat (France) and Hirtenberger (Austria), also loaded with Boxer primers.

\subsection{Procedure}

Primers were ignited using standard firing pins. Drop height was over $H_{100}(450 \mathrm{~mm})$ in order to provide $100 \%$ run. The firing pin was insulated and connected to the oscilloscope triggering channel. The cartridge case equipped with tested primer and steel balls inside (if desired) was introduced into the pressure measuring device, into its corresponding slot (loading chamber) and then the superior lid was screwed. The transducers and the firing pin were connected to the acquisition equipment. After percussion and primer ignition, the acquisition system recorded pressure vs. time curves. $t_{\mathrm{d}}, t_{\mathrm{f}}, p_{\max }$ and the shape of the curves were analysed, then transferred to databases in order to calculate other parameters. 


\section{Results and Discussion}

Numerous experiments have been performed on Romanian, French and Austrian primers. Typical tests results for one kind of primer are presented below in Tab. 3 and Fig. 4. Annotations used are according with those presented in chapter 2 and the other parameters are: $U_{\mathrm{k}}$ - "peak to peak" tension; $P_{\mathrm{k}}$ - maximum pressure for recorded $U_{\mathrm{k}}$; $A$ - amplitude of the electric signal, in terms of average tension; $P_{\text {med }}-$ average $P_{\max }$, corresponding to average tension delivered by charge amplifier and piezoelectric transducer. The rather high variations in the measured values can be explained based on the extremely small amounts of primer mixture in the percussion caps (around $20 \mathrm{mg}$ in each primer, see Tab. 2) while the granulation of the components is rather coarse for technological reasons.

Tab. 3 Typical values obtained for $5.56 \times 45$ Sadu primer, Batch $P$ (prototype) ( $V_{\exp }=0.984 \mathrm{~cm}^{3}<N=112$ balls, $\Delta$ t represents the $t_{\mathrm{d}}$ delay between the two transducers)

\begin{tabular}{|c|c|c|c|c|c|c|c|c|}
\hline \multirow[b]{2}{*}{ No. } & \multicolumn{6}{|c|}{ CHANNEL 1} & \multirow[b]{2}{*}{$\begin{array}{c}\Delta t \\
{[\mu \mathrm{s}]}\end{array}$} & \multirow[b]{2}{*}{$\begin{array}{c}V \\
{[\mathrm{~m} / \mathrm{s}]}\end{array}$} \\
\hline & $\begin{array}{c}t_{\mathrm{d}} \\
{[\mu \mathrm{s}]}\end{array}$ & $\begin{array}{c}t_{\mathrm{f}} \\
{[\mu \mathrm{s}]}\end{array}$ & $\begin{array}{c}U_{\mathbf{K}} \\
{[\mathbf{V}]}\end{array}$ & $\begin{array}{c}p_{\mathrm{K}} \\
{[\mathrm{bar}]}\end{array}$ & $\begin{array}{c}A \\
{[\mathrm{~V}]}\end{array}$ & $\begin{array}{c}p_{\text {med }} \\
\text { [bar] }\end{array}$ & & \\
\hline 1 & 166 & 168 & 1.68 & 21.6 & 0.92 & 11.9 & 34 & 529 \\
\hline 2 & 314 & 68 & 3.14 & 40.2 & 1.52 & 19.6 & 46 & 391 \\
\hline 3 & 280 & 82 & 2.32 & 30.0 & 1.72 & 22.2 & 44 & 409 \\
\hline 4 & 240 & 100 & 1.20 & 15.5 & 0.60 & 7.7 & 44 & 409 \\
\hline 5 & 276 & 66 & 3.08 & 39.7 & 1.48 & 19.1 & 32 & 562 \\
\hline 6 & 278 & 74 & 2.48 & 32.0 & 1.20 & 15.5 & 38 & 473 \\
\hline Average & 259 & 93 & 2.32 & 29.8 & 1.24 & 16.0 & 40 & 462 \\
\hline St. dev. & 51 & 39 & 0.77 & 9.8 & 0.42 & 5.4 & 5.85 & 71 \\
\hline
\end{tabular}

\begin{tabular}{|c|c|c|c|c|c|c|c|c|}
\hline \multirow[b]{2}{*}{ No. } & \multicolumn{6}{|c|}{ CHANNEL 2} & \multirow[b]{2}{*}{$\begin{array}{c}\Delta t \\
{[\mu \mathrm{s}]}\end{array}$} & \multirow[b]{2}{*}{$\begin{array}{c}V \\
{[\mathrm{~m} / \mathrm{s}]}\end{array}$} \\
\hline & $\begin{array}{c}t_{\mathrm{d}} \\
{[\mu \mathrm{s}]}\end{array}$ & $\begin{array}{c}t_{\mathrm{f}} \\
{[\mu \mathrm{s}]}\end{array}$ & $\begin{array}{c}U_{\mathbf{K}} \\
{[\mathrm{V}]}\end{array}$ & $\begin{array}{c}p_{\mathrm{K}} \\
{[\mathrm{bar}]}\end{array}$ & $\begin{array}{c}A \\
\text { [V] }\end{array}$ & $\begin{array}{c}p_{\text {med }} \\
{[\text { bar] }}\end{array}$ & & \\
\hline 1 & 200 & 184 & 1.56 & 18.0 & 0.76 & 8.8 & 34 & 529 \\
\hline 2 & 360 & 232 & 1.68 & 19.4 & 0.80 & 9.2 & 46 & 391 \\
\hline 3 & 318 & 138 & 1.72 & 19.8 & 0.88 & 10.1 & 44 & 409 \\
\hline 4 & 286 & 220 & 1.08 & 12.4 & 0.56 & 6.5 & 44 & 409 \\
\hline 5 & 306 & 116 & 2.16 & 24.9 & 1.04 & 12.0 & 32 & 562 \\
\hline 6 & 314 & 104 & 1.88 & 21.7 & 1.00 & 11.5 & 38 & 473 \\
\hline Average & 297 & 165 & 1.68 & 19.4 & 0.84 & 9.7 & 40 & 462 \\
\hline St. dev. & 53 & 54 & 0.36 & 4.16 & 0.18 & 2.0 & 6 & 71 \\
\hline
\end{tabular}


The data obtained for all ammunition tested was analysed and included in Tabs. 4a-c (as average values). Characteristics of primers measured using two pressure transducers were calculated and compared. Primers from Batch P (SADU) were considered as reference, as they were extensively tested in real firing in testing ranges using both $5.56 \mathrm{~mm}$ laboratory weapons and real $5.56 \mathrm{~mm}$ weapons. The hatchings in Tab. $4 \mathrm{a}, 4 \mathrm{~b}$ and $4 \mathrm{c}$ emphasize relative forces measured on channels 1 and 2 and then the average values from both channels.

The last column in Tab. 4c shows the classification of primer batches by relative force values. It can be observed that the rank is the same with or without balls simulating propellant charges. Batch 1, Batch 2 and Batch 3 primers were also tested in real firing tests with the complete ammunition and the classification after the results of comparing the ballistic performances was the same.

An interesting value presented in Tab. $4 \mathrm{c}$ is the pressure wave average velocity. This value along with the shape of the pressure vs. time curve indicate that the explosive transformation that occurs in tested primers is a one-stage process, while some works in the literature present initiation mechanism of primers as a two-stages process: detonation of primary explosive followed by the combustion of the pyrotechnic mixture.

The variables $t_{\mathrm{d}}$ and $t_{\mathrm{f}}$ are also decisive parameters for any ammunition, but especially for those used in automatic weapons. We only have to mention that long $t_{\mathrm{d}}+t_{\mathrm{f}}$ periods result in incomplete burning of the propellant and consequently lower energy for the projectile.

Similar experiments were performed using $9 \times 19 \mathrm{~mm}$ ammunition equipped with Boxer primers, produced by SADU Romania and GINEX Bosnia. Similar pressure vs. time measurements were performed for these primers. During the tests there were fired three types of primers, two leaded with "toxic" mixtures (based on lead styphnate, barium nitrate and antimony sulphide) and one lead-free with "non-toxic" mixture (based on diazodinitrophenol (DDNP), zinc peroxide and Ti powder). The average results (from ten shots) are summarized in Tab. 5 and typical pressure vs. time curves are indicated in Fig. 4.

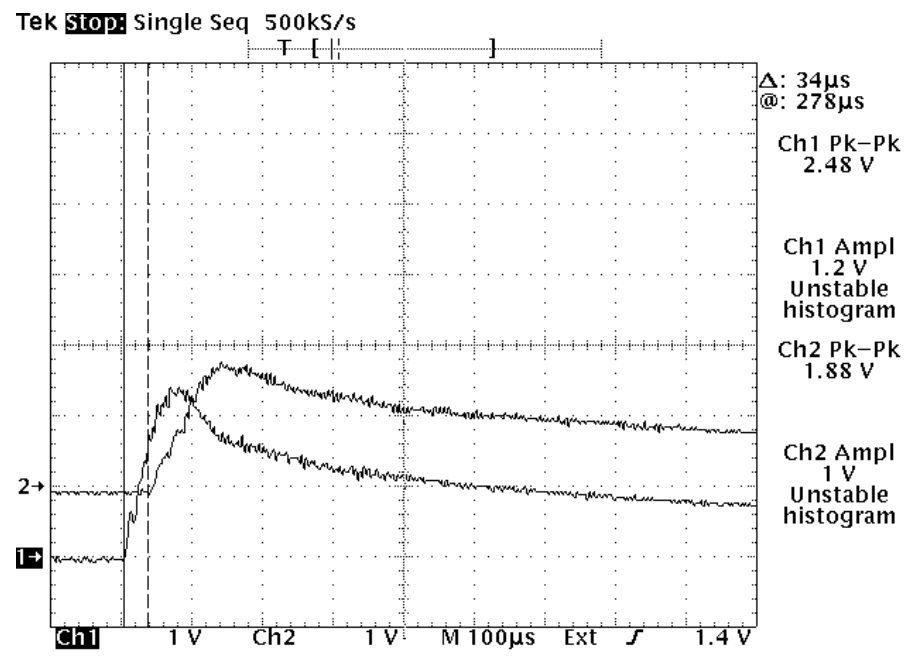

Fig. 3. Typical pressure vs. time curve for $5.56 \times 45$ ammunition 
Tab. 4a Average values on first transducer (channel 1)

\begin{tabular}{|c|c|c|c|c|c|c|c|c|c|c|}
\hline 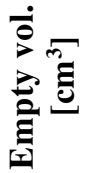 & 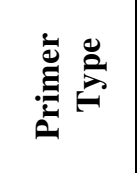 & $=\bar{\Omega}$ & $=\sqrt{3}$ & 胥 & 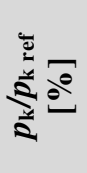 & 总 & 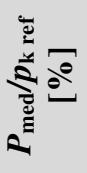 & 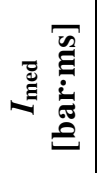 & 氧 & 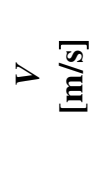 \\
\hline \multirow{4}{*}{9} & Batch P & 488 & 135 & 43.1 & 100 & 21.4 & 100 & 14.4 & 488 & 809 \\
\hline & Batch 1 & 516 & 134 & 36.2 & 84 & 19.3 & 90 & 12.9 & 516 & 744 \\
\hline & Batch 2 & 512 & 125 & 47.0 & 109 & 27.5 & 128 & 17.2 & 512 & 995 \\
\hline & Batch 3 & 461 & 129 & 41.1 & 95 & 23.8 & 44 & 15.4 & 461 & 950 \\
\hline \multirow{4}{*}{$\stackrel{9}{-}$} & Batch P & 373 & 184 & 34.6 & 100 & 19.4 & 100 & 17.8 & 373 & 816 \\
\hline & Batch 1 & 476 & 114 & 40.0 & 115 & 19.8 & 102 & 11.2 & 476 & 944 \\
\hline & Giat & 393 & 134 & 71.3 & 206 & 26.7 & 137 & 17.9 & 393 & 1012 \\
\hline & Hirtenb. & 522 & 112 & 52.3 & 151 & 27.4 & 141 & 15.3 & 522 & 827 \\
\hline \multirow{6}{*}{$\begin{array}{l}+ \\
\infty \\
\vdots \\
0\end{array}$} & Batch P & 254 & 93 & 29.8 & 100 & 16.0 & 100 & 7.44 & 254 & 421 \\
\hline & Batch 1 & 486 & 128 & 26.4 & 88 & 12.6 & 79 & 8.06 & 486 & 380 \\
\hline & Batch 2 & 368 & 117 & 32.1 & 107 & 18.8 & 118 & 11.0 & 368 & 723 \\
\hline & Batch 3 & 429 & 99 & 30.4 & 102 & 15.9 & 99 & 7.87 & 429 & 672 \\
\hline & Giat & 440 & 76 & 50.8 & 170 & 24.9 & 155 & 9.46 & 440 & 665 \\
\hline & Hirtenb. & 305 & 67 & 47.1 & 158 & 24.9 & 156 & N/A & 305 & 408 \\
\hline
\end{tabular}

Tab. 4 b Average values on the second transducer (channel 2)

\begin{tabular}{|c|c|c|c|c|c|c|c|c|c|}
\hline 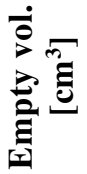 & 离 & $=\frac{\pi}{3}$ & $=\overline{\underline{\Omega}}$ & 㐘 & 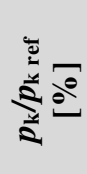 & 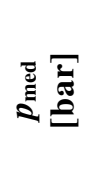 & 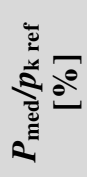 & 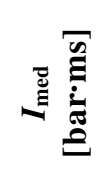 & 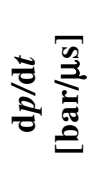 \\
\hline \multirow{4}{*}{$\stackrel{9}{-}$} & Batch P & 513 & 54 & 45.2 & 100 & 22.0 & 100 & 5.64 & 4.07 \\
\hline & Batch 1 & 540 & 30 & 40.6 & 90 & 25.7 & 116 & 3.85 & 8.56 \\
\hline & Batch 2 & 530 & 29 & 54.3 & 120 & 39.0 & 177 & 5.66 & 13.5 \\
\hline & Batch 3 & 481 & 27 & 48.8 & 107 & 30.4 & 138 & 4.10 & 11.3 \\
\hline \multirow{4}{*}{9} & Batch P & 420 & 112 & 42.0 & 100 & 24.2 & 100 & 13.5 & 2.16 \\
\hline & Batch 1 & 495 & 52 & 37.0 & 88 & 18.1 & 74 & 4.71 & 3.48 \\
\hline & Giat & 411 & 53 & 89.3 & 212 & 59.4 & 245 & 15.7 & 11.2 \\
\hline & Hirtenb. & 545 & 38 & 56.9 & 135 & 30.0 & 124 & 5.7 & 7.9 \\
\hline \multirow{6}{*}{ 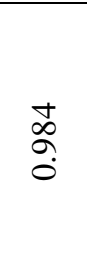 } & Batch P & 297 & 164 & 19.4 & 100 & 9.7 & 100 & 7.95 & 0.59 \\
\hline & Batch 1 & 535 & 130 & 19.3 & 99 & 10.6 & 109 & 13.8 & 0.81 \\
\hline & Batch 2 & 395 & 164 & 24.6 & 126 & 11.9 & 122 & 9.76 & 0.72 \\
\hline & Batch 3 & 457 & 121 & 22.9 & 118 & 11.1 & 114 & 6.71 & 0.91 \\
\hline & Giat & 470 & 110 & 38.2 & 197 & 19.2 & 197 & 10.6 & 1.74 \\
\hline & Hirtenb. & N/A & 58 & 33.2 & 171 & 19.4 & 200 & 5.63 & 3.34 \\
\hline
\end{tabular}


Tab. 4c Comparison of the results

\begin{tabular}{|c|c|c|c|c|c|c|c|}
\hline 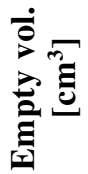 & $\stackrel{\vdots}{\Xi}$ & $>\stackrel{\tilde{\sigma}}{\Xi}$ & 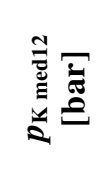 & 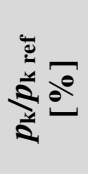 & 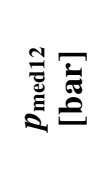 & 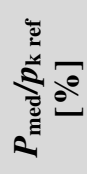 & \\
\hline \multirow{4}{*}{$\stackrel{-}{-}$} & Batch P & 809 & 44.2 & 100 & 21.7 & 100 & III \\
\hline & Batch 1 & 744 & 38.4 & 87 & 22.5 & 104 & IV \\
\hline & Batch 2 & 995 & 50.7 & 115 & 33.2 & 153 & I \\
\hline & Batch 3 & 950 & 44.9 & 101 & 27.1 & 124 & II \\
\hline \multirow{4}{*}{$\stackrel{\rho}{9}$} & Batch P & 816 & 38.3 & 100 & 21.8 & 100 & III \\
\hline & Batch 1 & 944 & 38.5 & 101 & 19.0 & 87 & IV \\
\hline & Giat & 1012 & 80.3 & 209 & 43.1 & 197 & I \\
\hline & Hirtenberg & 827 & 54.6 & 143 & 28.7 & 131 & II \\
\hline \multirow{6}{*}{ 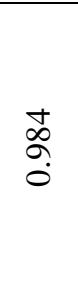 } & Batch P & 421 & 24.6 & 100 & 12.9 & 100 & III \\
\hline & Batch 1 & 380 & 22.9 & 93 & 11.6 & 90 & IV \\
\hline & Batch 2 & 723 & 28.3 & 115 & 15.4 & 119 & I \\
\hline & Batch 3 & 672 & 26.7 & 109 & 13.5 & 104 & II \\
\hline & Giat & 665 & 44.5 & 181 & 22.0 & 170 & - \\
\hline & Hirtenberg & 408 & 40.2 & 163 & 22.2 & 172 & - \\
\hline
\end{tabular}

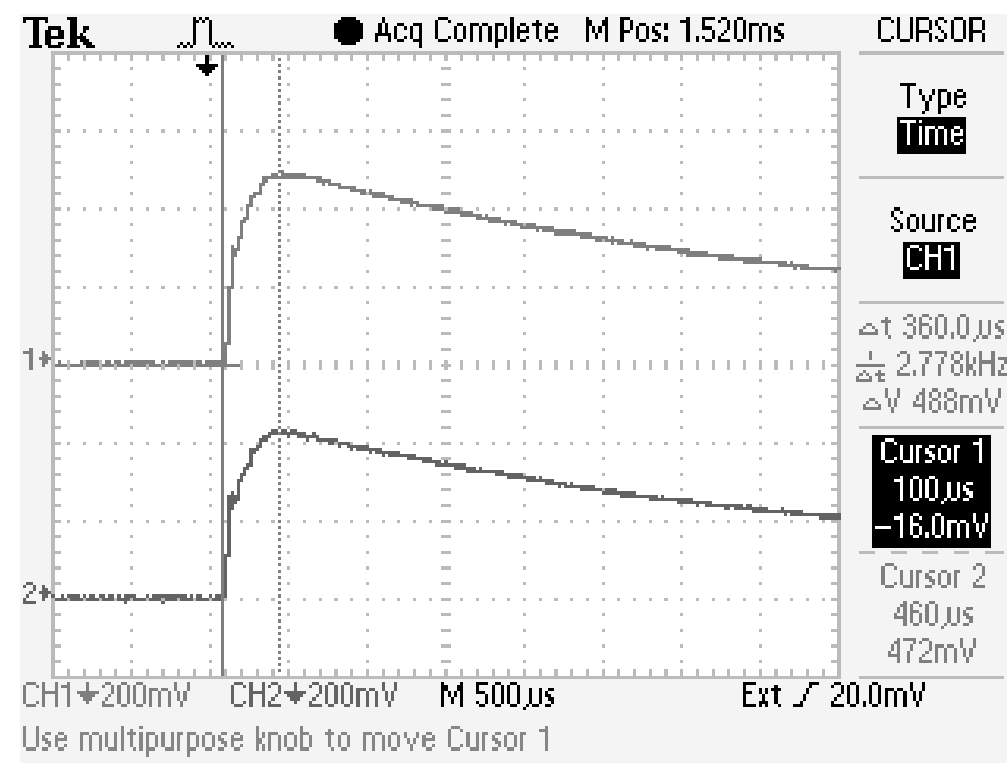

Fig. 4a Pressure versus time curve for leaded primer and for lead-free primer, respectively Lead-containing primer (TNR-Pb) 


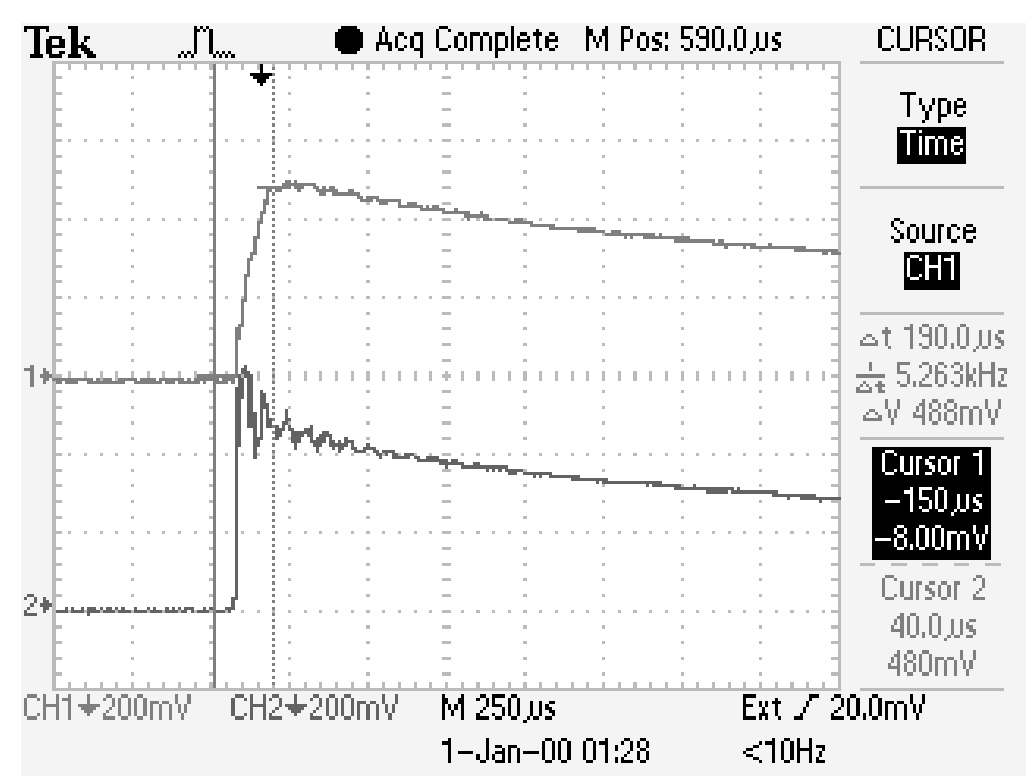

Fig. 4a Pressure versus time curve for leaded primer and for lead-free primer, respectively Lead-free primer (DDNP)

The results indicate that even if the average pressure is similar, lead-free primers have a shorter functioning time. That information is extremely valuable, for example, when analysing the possibility of using these two kinds of percussion primers in automatic armament systems.

Tab. 5 Average values of the main parameters

\begin{tabular}{|c|c|c|c|}
\hline $\begin{array}{c}\text { Primer } \\
\text { type }\end{array}$ & $\boldsymbol{t}_{\mathbf{f}}[\mathbf{s}]$ & $\boldsymbol{U}_{\mathbf{M}}[\mathbf{V}]$ & $\boldsymbol{P}_{\mathbf{M}}[\mathbf{b a r}]$ \\
\hline \hline Leaded SADU Romania & 191 & 0.51 & 50.80 \\
\hline Leaded GINEX Bosnia & 365 & 0.53 & 53.04 \\
\hline Lead-free GINEX Bosnia & 173 & 0.52 & 51.47 \\
\hline
\end{tabular}

\section{Conclusions}

The ignition performance of the priming system represents an important parameter for the entire explosive train in any ammunition. Previous theoretical and experimental studies on percussion primers performances only emphasized the complexity of the matter.

In this regard, a method has been developed to comparatively asses the ignition performances of percussion primers. Since primer ignition capacity cannot be determined as an absolute value, it can be measured versus a reference primer. Knowing the relative ignition capacity of a primer is very important when investigating / developing new types of priming mixtures. It allows facile testing of different formulations without doing final assembling of the ammunition and performing live ammunition tests in the firing range.

The authors developed a testing procedure using standard equipment for ballistic measurements EPVAT (pressure transducers, charge amplifiers, data acquisition 
systems, etc.) and a special design pressure vessel (combustion chamber) in order to measure pressure vs. time curve generated by a primer, along the cartridge case.

The method described above allowed us to determine some primer characteristics inaccessible until now, such as delay or function time, pressurizing velocity, influence of free volume. By knowing these values, a quantitative tool for comparing different designs of primers for specific ammunitions and also for specific armament system has been obtained.

Tests results indicate a strong relationship between the ballistic characteristics of primers ( $p_{\max }$ and relative force) and the ballistic characteristics of the corresponding ammunition. In other words, it is possible to adjust the ballistic performances of the primer prior its use in a real ammunition / weapon system.

The velocity of the pressure wave determined during the tests by using multiple transducers show that primer mixtures are submitted to a single-stage process of explosive transformation and not a two-stage process (detonation-combustion).

\section{References}

[1] TRANĂ, E. and ROTARIU, A. Aspects Regarding Mechanical Properties of a Triple Base Propellant and their Influence on Interior Ballistic Cycle. MTA Review, 2014, vol. XXIV, no.2, p. 83-89.

[2] ŠTRBA, J. and KUSÁK, J. Geometric Coefficients Modifications of Surface Non-Treated Seven-Perforated Nitrocellulose Powder. Advances in Military Technology, 2011, vol. 6, no. 1, p. 47-56. ISSN 1802-2308.

[3] JANKOVÝCH, R. and MAJTANÍK, J. Quantitative Safety Risk Requirements for Small Arms and Ammunition. Advances in Military Technology, 2008, vol. 3, no. 1, p. 5-16. ISSN 1802-2308.

[4] RITTER, J.J. Characterizing 5.56-mm Cartridge Performance with Novel Measurement Techniques. International Journal of Energetic Materials and Chemical Propulsion, 2013, vol. 12, no. 4, p. 361-370.

DOI 10.1615/IntJEnergeticMaterialsChemProp.2013005291

[5] GOGA, D.A. Design and Construction of Pyrotechnic Initiation Devices (in Romanian), Bucharest: Military Technical Academy, 2002, 240 p.

[6] BELGRAMO, C. The Explosives (in Italian). Udine: Editura Arti Grafiche Friulane, 1974, $365 \mathrm{p}$.

[7] PEUGEOT, F. Etude de la Sensibilité des Explosifs à la Pénétration par Percussion à Faible Energie (in French), Poitiers: ENSIETA, 1995.

[8] FERREIRA, C., RIBEIRO, J., ALMADA, S., ROTARIU, T. and FREIRE, F. Reducing Impacts from Ammunitions: a Comparative Life-Cycle Assessment of Four Types of $9 \mathrm{~mm}$ Ammunitions. Science of the Total Environment, 2016, vol. 566-567, p. 34-40. DOI 10.1016/j.scitotenv.2016.05.005

[9] PETRE, R., ROTARIU, T., ZECHERU, T., PETREA, N. and BĂJENARU, S. Environmental Long Term Impact on a Romanian Military Testing Range. Central European Journal of Energetic Materials, 2016, vol. 13, no. 1, p. 3-19. ISSN 1733-7178.

[10] ROtARIU, T., PETRE, R., ZECHERU, T., SUCESKA, M., PETREA, N. and EŞANU, S. Comparative Study of $9 \times 19 \mathrm{~mm}$ Ammunition Combustion Products 
and Residues. Propellants, Explosives and Pyrotechnics, 2015, vol. 40, no. 6, p. 931-937.

[11] KLAPOETKE, T.M. Chemistry of High-Energy Materials. $2^{\text {nd }}$ ed. Berlin/Boston: de Gruyter, 2012, p. 209.

[12] STIASNY, B., KLAPOETKE, T., STIERSTORFER, J., WIEGMANN, S., ROTARIU, T. and ZECHERU, T., Azido(tert-butylperoxy)methyl Compounds an Interesting Class of Energetic Materials. European Journal of Organic Chemistry, 2016, vol. 2016, no. 25, p. 4382-4386. DOI 10.1002/ejoc.201600717.

[13] Manual of Proof and Inspection Procedures for NATO $5.56 \mathrm{~mm}$ Ammunition. Brussels: NATO, 2003.

[14] Manual of Proof and Inspection for $9 \mathrm{~mm}$ Ammunition AC/225 (P111-SP1) D/170(REV). Brussels: NATO, 1982. 